Int. J. Dev. Biol. 53: 1269-1271 (2009)

doi: $10.1387 / \mathrm{ijdb} .072461 \mathrm{fc}$

\title{
Iberia: from fable to the bench
}

\author{
FERNANDO CASARES* \\ CABD, CSIC-Universidad Pablo de Olavide, Sevilla, Spain and IBMC, Universidade do Porto, Porto, Portugal
}

\begin{abstract}
Developmental Biology in Portugal and Spain has been running along mostly parallel tracks - until recently. It is the youngest generations who, driven by an increasing interest in the science and culture of each other's country, are bringing the situation to its natural state: one of strong and fruitful collaboration between Iberian labs.
\end{abstract}

KEY WORDS: Portugal, Spain, GABBA PhD programme, developmental biology, collaboration

Developmental biology was born earlier in Spain than in Portugal. In the form of Developmental Genetics, the Madrid school of drosophilists at the Centro de Biologia Molecular (CBM) became a beacon for the discipline in the late 70's and early 80's. This school, initiated by Antonio García-Bellido and pushed forward by Ginés Morata and Juan Modolell, would later radiate to seed other parts of Spain through the founders' progenies, who had been further trained abroad as postdoctoral researchers. Together with the "Drosophila radiation", several other groups were growing all over the country filling in other niches of the discipline. Especially relevant has been the merge of the neuroanatomical tradition of the Ramón y Cajal school with the genetic and molecular study of the development of the nervous system. These two colossal influences have had a strong positive impact on Spanish Developmental Biology, and perhaps some side-effects. On the one hand, they have sheltered and nurtured the growth of modern Spanish Developmental Biology. On the other, they have determined to some extent the experimental approaches and questions the Spanish community was to study. In any case, it took science policy makers surprisingly long to realize the potential of Developmental Biology in Spain, and it has only been during the last decade that research institutes and university departments throughout the Spanish geography have started, or beefed up their DevBiol sections. Therefore, Developmental Biology is currently in full blow in Spain compared to what it used to be only a couple of decades ago. More developmental biologists are being recruited, either through national calls (including the five-year Ramón y Cajal career development program) or through autonomous regional governments (such as the ICREA program), which are not only boosting human capital, but also introducing a lot of diversity. In addition, Developmental Biology has benefited from the recent steady increase in funding from the Spanish government, the capacity of some groups to secure EU money, and the novel interest of the autonomous regional governments to sup- port biomedical research under conditions of "healthy" competition. The critical mass issue is being resolved and this mass is now less centralized.

The expansive wave going on in Spain in the 80s and 90s did not cross its western border (a border that, until recently, has been historically impermeable in both directions). The late arrival of DevBiol to Portugal may have been due in part to the attractor effect of the mainstream research lines in Portugal, human genetics and immunology. Apart from some precursors, at the turn of the millennium, Developmental Biology in Portugal was reduced to a few groups at the Gulbenkian Science Institute (IGC), in Oeiras (close to Lisbon) and my own, established the Institute for Molecular and Cell Biology (IBMC) in Oporto. This situation has offered some advantages in the Portuguese context. First, the first developmental biologists in the country, young and trained abroad, found an empty, albeit small, scientific niche to colonize. Some of these groups have already moved "centrifugally" to other locations (University of Minho, University of Algarve...) and have started their labs there. Second, a number of excellent PhD programs have been brewing a new generation of bioscientists that include developmental biologists, some of which are returning to Portugal after completing their PhDs and postdocs, in what seems to have become a self-reinforcing trend. The Portuguese hiring system benefits from its flexibility when compared to the Spanish one: the research institutes can select and recruit their staff using their own budgets, not necessarily through national calls. The Spanish National Research Council (CSIC or Consejo Superior de Investigación Científica) research centers will move towards a similar flexible management, with the much-awaited transformation of the CSIC into a governmental

Abbreviations used in this paper: CBM, Centro de Biología Molecular; GABBA, Graduate Programme in Basic and Applied Biology.

*Address correspondence to: Fernando Casares. CABD, CSIC-Universidad Pablo de Olavide. 41013 Sevilla, Spain. e-mail: fcasfer@upo.es

ISSN: Online 1696-3547, Print 0214-6282

(C) 2009 UBC Press

Printed in Spain 
agency. In addition, Portuguese science is more used than the Spanish system to "importing" foreign scientists. This is because, among other things, job interviews and any official communications with the Portuguese funding agencies (mostly the Fundação para a Ciência e a Tecnologia, FCT) are routinely conducted in English. This is transforming the Portuguese DevBiol panorama into a very international one.

Of course, not having templates at home is always difficult. But also the lack of templates allows scientists to move in original directions. In any case, the Portuguese DevBiol crew is moving forward quickly: The Portuguese Developmental Biology Society inaugurated its activity with an excellent meeting in 2006 (see Andrade and Saúde, 2007), followed by this 2007 Mechanisms of Early Development organized at the IMM (Institute for Molecular Medicine, Lisbon), itself a newly founded biomed research institute with a well staffed DevBiol department. Still, the growth of Developmental Biology will be jeopardized if national funding is not increased and if the calls for proposals are not regular. Another hindrance to growth will be if not enough jobs with reasonable start-up packages are offered, and that needs more departments and new research institutes. Portugal is still lacking its own critical mass in the area. The new Ciencia program will allow research institutions to open five-year positions to meet this need.

So this has been the scenario up to now. With some notable exceptions, there are few collaborations between Portuguese and Spanish groups. Most of the interactions are reduced to Spanish scientists being invited as external examiners in PhD defense committees. But this is changing swiftly - and this Special Issue of the Int. J. Dev. Biol. is proof of it.

Stating the obvious, the first and easiest step to foster lberian Developmental Biology is to establish contacts among scientists of the two countries. In spite of web pages and emails, very often the best collaborations are built only after one knows, likes and trusts his/her collaborators. Not to mention that most interesting ideas emerge from good chats. The two countries should use their respective societies as facilitators, celebrating periodic joint meetings. A good first occasion was the most recent SEBD meeting, which took place in Seville, jointly with the British Society for Developmental Biology, hosted by the Centro Andaluz de Biología de/ Desarrollo (CABD) (for a report of the meeting, see Hidalgo and Martín-Bermudo, 2009).

An immediate benefit of this communication would be the identification of large/expensive/specialized services and technological platforms that could be made available to researchers from both sides of the border in a similar way that EU countries chip in to share, say CERN facilities. Shared access to these facilities could save money, avoid duplicating equipments and attract funding, especially if there is geographical proximity between the interested labs. This catalogue of equipment should also include an inventory of technical expertise, to facilitate identifying the specific expert one needs.

Another way of fostering scientific productivity through collaborations could be to fund joint Portuguese/Spanish research projects. Currently, this can be achieved within large conglomerates through EU FP projects, that are not suited for smaller scale collaborations which are often more productive when the outcome/money invested ratio is considered. Also, the Spanish CSIC and Ministry of Education and Science (MEC) and the Portuguese Foundation for Science and Technology (FCT) fund travel grants. These are very useful to support short research stays, or visits between researchers interested in exploring a collaboration, but not to launch joint projects (that is, buying consumables, hiring researchers, etc.). Grants for joint Portuguese/Spanish research projects would not be necessarily large, but sufficient to set in motion pilot projects with potential to expand.

But it is on students and postdocs where we need to place the most serious efforts to consolidate one strong community of developmental biologists in the Iberian Peninsula. The interest is already there: students and postdocs from both countries are already crossing the border looking for very good science, interested in each other's culture and, in addition, staying pretty close to home. Alluring the best Portuguese and Spanish young brains to Developmental Biology -and to work in either country-could be immensely facilitated through joint PhD programs. In these, a number of institutions may join to offer complementary training and jobs. All kinds of variations could be imagined, including joint $\mathrm{PhD}$ or postdoctoral positions similar to the program offered by the European Molecular Biology Laboratory (EMBO), where each student chooses to work in two labs tackling related problems using complementary approaches. But a good reference could be any of the great PhD programs Portuguese institutions are currently offering. These programs are characterized by being highly selective, international (they accept EU students without the burden of bureaucratic validations of their titles) and funded, with a four-year fellowship. In these programs the students are offered a year of intensive training (mostly lecture courses, though) and the possibility of choosing, anywhere in the world, the lab they want to go for their thesis work (including, of course, labs in Portugal or the option of combining one Portuguese lab and another abroad). Of course, offering a good fellowship is great to attract good individuals. And motivated, bright students with a fellowship are all a lab head dreams of. The GABBA (Graduate Program in Basic and Applied biology) of University of Porto has been a pioneer in "outsourcing" some of their courses to Spain in what could be taken as an example of future crossborder cooperation. In particular, José Luis Gómez-Skarmeta and I have been organizing the GABBA Developmental Biology module at CABD, Seville. Here, the GABBAs (as the students like calling themselves) spend a first week of intensive lectures given by local and invited researchers, with some incursion to the lab. During the second week students are immersed in lab work and spend their day, and part of their evenings, genetically labeling cells, sorting them and asking for their proliferation characteristics, bugging $C$. elegans, generating GFP-expressing zebrafish transgenics that they will be able to image in living embryos, injecting RNAs into Xenopus early zygotes and testing the whole-body organizing capacities of morphogens or using bioinformatics tools to design research projects aimed at developing animal models for human disease. So far, the experiences of both students and lecturers/ instructors have been excellent, to the extent that next year, this humble course will expand to also include, in addition to the twelve GABBAs, another fifteen students who will be recruited through an international call -and that will be supported by the EU Network of excellence "From Cells to Organs", among others. In three Sevilla editions, several students decided to stay in Spanish developmental biology labs. It is interesting to mention that this course has been generated almost spontaneously. That is, through 
the identification of the scientific need in the program and the enthusiasm of the participants, without involving long institutional negotiations. And thanks, to a great extent, to the flexibility and foresight of the Portuguese scientists behind the GABBA program and to the fact that most of the participant lecturers, mostly working in Spain and Portugal, not only appreciate each other's work, but get along well.

But, if I had to point out the most compelling reason for strengthening the relationships between developmental biologists across the border, I would say that is a personal one. After having been living and working in both countries, it feels unnatural not to think and work together. José Saramago [a Nobel-laureate Portuguese novelist, playwright and journalist], a maker of great human fables, has been talking lately of "Iberia". Far from trying to be a political description, I believe he means that natural situation in which all cultures in the Iberian Peninsula integrate, very much like how the development of the organs of an embryo, albeit somehow independent modules, grow coordinately. Developmental biology in lberia must turn a fable into reality.

\section{Acknowledgements}

To Juan Aréchaga and Carmo Fonseca for inviting me to contribute to this issue. To José Luis Gómez-Skarmeta, James Castelli-Gair and Antonio Jacinto for comments.

\section{References}

ANDRADE, R.P. and SAÚDE, L. (2007). First Meeting of the Portuguese Society for Developmental Biology (SPBD). Int. J. Dev. Biol. 51: 177 - 182.

HIDALGO, A. and MARTIN-BERMUDO, L. (2009). 1st joint meeting of the British and Spanish Developmental Biology Socities. Int. J. Dev. Biol. 53: 443-446.

\section{Further Related Reading, published previously in the Int. J. Dev. Biol.}

See our Special Issue Developmental Genetics of Drosophila edited by Alain Ghysen at: http://www.ijdb.ehu.es/web/contents.php?vol=42\&issue=3

See our recent Special Issue Fertilization, in honor of David L. Garbers and edited by Paul M. Wassarman and Victor D. Vacquier at:

http://www.ijdb.ehu.es/web/contents.php?vol=52\&issue =5-6

Ontogeny of an adventurous mind: the origin of Antonio García-Bellido's contributions to developmental genetics

Alain Ghysen

Int. J. Dev. Biol. (2009) 53: 1277-1290. (doi: 10.1387/ijdb.072384ag)

Plant Developmental Biology in Spain: from the origins to our days and prospects for the future

José-Pío Beltrán

Int. J. Dev. Biol. (2009) 53: 1219-1234. (doi: 10.1387/ijdb.072456jb)

Using fruitflies to help understand the molecular mechanisms of human hereditary diffuse gastric cancer

Joana Caldeira, Paulo S. Pereira, Gianpaolo Suriano and Fernando Casares

Int. J. Dev. Biol. (2009) 53: 1557-1561. (doi: 10.1387/ijdb.072277jc)

5th Congress of the Spanish Society of Developmental Biology

Jaume Baguñà

Int. J. Dev. Biol. (2007) 51: 91-96

First Meeting of the Portuguese Society for Developmental Biology (SPBD)

Raquel P. Andrade and Leonor Saúde

Int. J. Dev. Biol. (2007) 51: 177-182

In defense of pure science: Antonio García-Bellido.

F C Kafatos

Int. J. Dev. Biol. (1998) 42: 539-540

The genetic logic of Antonio García-Bellido.

G A Dover

Int. J. Dev. Biol. (1998) 42: 535-538

Debatable issues. Interview with L Wolpert and A García-Bellido.

Alain Ghysen

Int. J. Dev. Biol. (1998) 42: 511-518

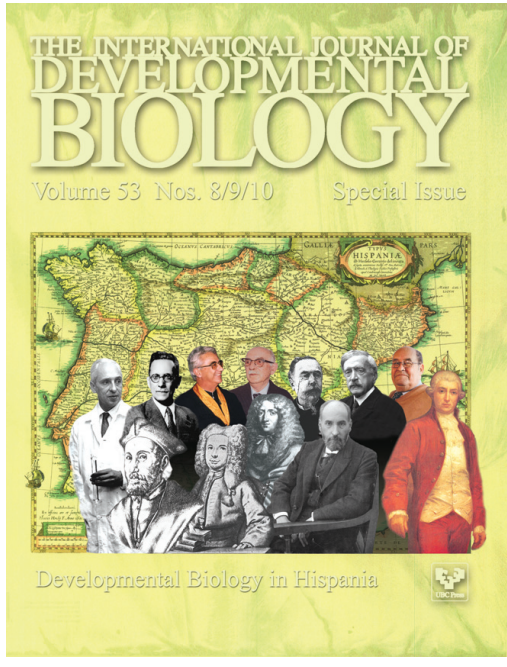

5 yr ISI Impact Factor $(2008)=3.271$

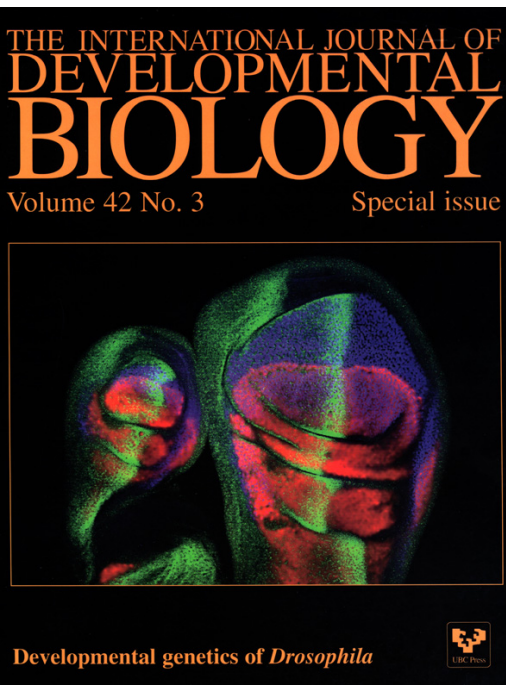

